Dicle Tıp Dergisi / Dicle Med J (2018) 45 (3) : 237-244

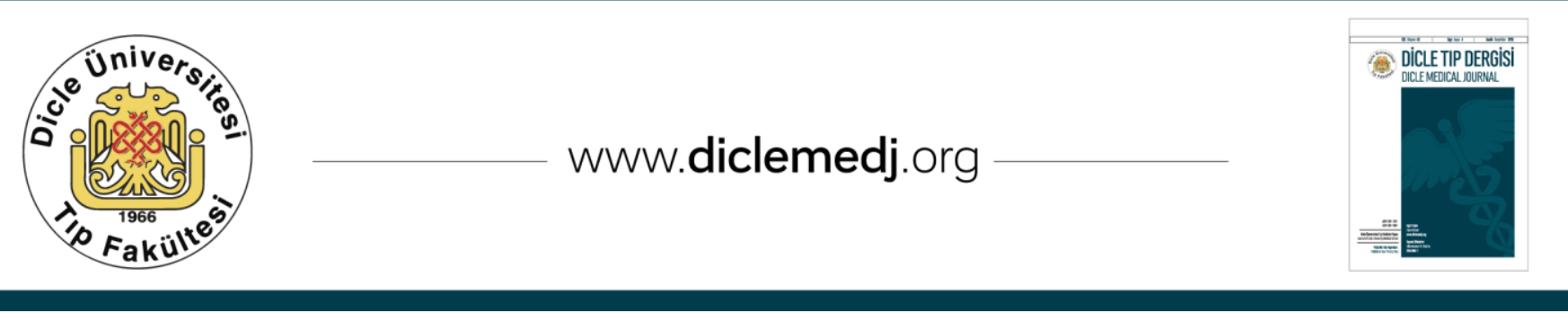

Özgün Araştırma / Original Article

\title{
Greft sağkalımını etkileyen faktörlerin transplant böbrek biyopsileriyle değerlendirilmesi
}

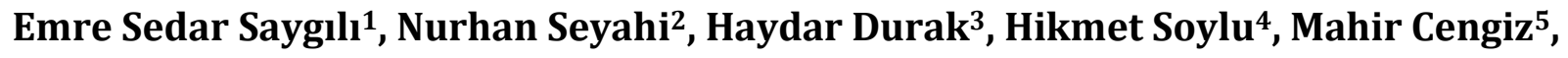 \\ Mehmet Riza Altıparmak 6 \\ 1 Sağlık Bilimleri Üniv Şişli Hamidiye Etfal Eğitim ve Araştırma Hastanesi Endokrinoloji ve Metabolizma Kliniği, İstanbul, Türkiye \\ ORCID: 0000-0003-0022-5704 \\ 2 Istanbul Universitesi Cerrahpaşa Tıp Fakültesi, İç hastalıkları Ana Bilim Dall, Nefroloji Bilim Dalı, İstanbul, Türkiye ORCID: 0000-0001-7427-618X \\ 3 Istanbul Universitesi Cerrahpaşa Tip Fakültesi, Patoloji Ana Bilim Dal, İstanbul, Türkiye ORCID: 0000-0003-2299-6606 \\ 4 Dicle Üniv Tıp Fakültesi, İç hastalıkları Ana Bilim Dalı, Endokrinoloji ve Metabolizma Bilim Dalı. İstanbul, Türkiye ORCID: 0000-0003-4118-366X \\ 5 Istanbul Universitesi Cerrahpaşa Tıp Fakültesi, İç hastalıkları Ana Bilim Dal, İstanbul, Türkiye ORCID: 0000-0003-3343-8650 \\ 6 Istanbul Universitesi Cerrahpaşa Tıp Fakültesi, İç hastalıkları Ana Bilim Dalı, Nefroloji Bilim Dall, İstanbul, Türkiye 0RCID: 0000-0002-3579-1100
}

Geliş: 14.11.2017, Revizyon: 28.05.2018, Kabul Tarihi: 07.06.2018

$\ddot{0} \mathbf{z}$

Amaç: Uzun dönemdeki surviye ve allograft fonksiyonuna etkili olan faktörler her merkezde farklılıklar gösterebilmektedir. Bu nedenle ünitemizden takipli renal allograft biyopsi yapılmış olan hastaların biyopsi sonuçları ve greft sağ kalımları arasındaki ilişkilerin değerlendirilmesi amaçlanmıştır.

Yöntemler: 70 hastaya yapılan 94 adet biyopsi retrospektif olarak incelemiştir. Ultrason rehberliğinde tek kullanımlık $16 \mathrm{G}$ otomatik iğne ile 2 kore biyopsi alınmıştır. Her biyopsi ışık mikroskopisi ve immunfloresan boyama ile incelenmiștir. Hastalar akut selüler rejeksiyon (ASR), kalsinörin inhibitörü(KNI) toksisitesi, intersitisyel fibrozis tübüler atrofi (IFTA), akut tubüler hasar(ATH) ve greft kaybı gelişenler olarak gruplara ayrılarak alt analizleri yapılmıştır.

Bulgular: Toplamda 34(\%36,2) biyopsi ile en sık tespit edilen patolojiyi akut selüler rejeksiyon oluşturmaktadır. IFTA, ATH, nüks/de novo glomerülonefrit biyopsi sayıları sırasıyla 21(\%22,3), 20(\%21,3), 15(\%16) olarak bulunmuștur. Akut rejeksiyon öyküsü olanlarda greft sürvisinin daha kısa olduğu tespit edilmiştir $(\mathrm{p}<0.05)$. Greft kaybı olan grupta IFTA daha fazla görülmüştür $(\mathrm{p}<0.05)$. Surviler logrank testi ile IFTA ya göre kıyaslandığında istatistiksel anlamlılığını yitirmiştir. Çalıșmaya alınan hastalarda KNI toksisitesi, ATH ile greft sürvileri arasında anlamlı fark tespit edilememiştir. Biyopsi sırasındaki albümin seviyesi greft kaybı olan grupta anlamlı olarak daha düşük bulunmuştur $(\mathrm{p}<0.05)$.

Sonuç: Biyopsilerin yaklaşık üçte birinde öntanıdan farklı bir tanı ile karşılaşılmıştır. Bu da biyopsi olmadan diğer klinik ve laboratuvar bulguların yetersizliğini göstermektedir. Greft survisini ön görmede biyopsi önemli yer teşkil etmektedir. Non-invaziv olarak biyopsi öncesi bakılan serum albumin seviyesi greft kaybını öngörmede bir parametre olarak değerlendirilebilir.

Anahtar Kelimeler: Böbrek nakli, Biyopsi, Patoloji, Sağkalım.

DOI: $10.5798 /$ dicletip.457229

Yazışma Adresi / Correspondence: Emre Sedar Saygılı, Şişli Hamidiye Etfal Eğitim ve Araştırma Hastanesi Halaskargazi Cad. Etfal Sk. 34371 Şişli / İstanbul, Türkiye e-mail: $\underline{\text { dr.emresaygili@gmail.com }}$ 


\title{
Evaluation of factors influencing graft survival by transplant kidney biopsies
}

\begin{abstract}
Objective: Factors affecting long-term survival and allograft function may differ in each center. Therefore, it is aimed to evaluate the relation between biopsy results and graft survival of patients who have undergone renal allograft biopsy.

Methods: We retrospectively analyzed 94 biopsies of 70 renal transplant recipients. Disposable $16 \mathrm{G}$ needles were used to perform 2 ultrasound-guided core biopsies. Each specimen was examined under light and immunofluorescence microscopy. Patients were divided into acute cellular rejection (ACR), calcineurin inhibitor (CNI) toxicity, graft loss, interstitial fibrosis tubular atrophy (IFTA), acute tubular damage (ATD) groups and analyzed.

Results: The most frequent pathology was ACR, diagnosed in total of $34(36.2 \%)$ specimens. IFTA, ATD and recurrent de novo glomerulonephritis biopsy were 21 (22.3\%), 20 (21.3\%) and $15(16 \%)$, in number, respectively. Graft survival in patients with a history of acute rejection was shorter than without history $(\mathrm{p}<0.05)$. IFTA was more common in the group with loss of graft $(p<0.05)$. When compared with survival in log-rank test IFTA have lost their statistical significance. There was no significant difference between CNI toxicity, ATD and graft survival. Graft loss was more common in patients with lower albumin levels during biopsy $(\mathrm{p}<0.05)$.

Conclusions: Approximately one third of the biopsies were diagnosed differently than presumed. This demonstrates the inadequacy of other clinical and laboratory findings without biopsy. Renal allograft biopsy is an important tool to predict graft survival. Serum albumin level before biopsy can be considered as a parameter for predicting loss of graft.
\end{abstract}

Keywords: Kidney Transplantation, Biopsy, Pathology, Survival.

\section{GíRis}

Böbrek nakli son dönem böbrek yetersizliğinin en iyi tedavi seçeneğidir. Diyaliz ile kıyaslandığında yaşam kalitesi ve sağkalım açısından birçok üstünlükleri mevcuttur ${ }^{1}$. Kısa dönem greft sağkalımında ciddi iyileşmeler sağlanmasına rağmen, aynı durum ne yazık ki uzun dönem greft sağkalımı için geçerli değildir².

Renal allograft disfonksiyonunun araştırılmasında en önemli inceleme yöntemi allograft biyopsisidir ${ }^{3,4}$. Post-transplant dönemde birçok klinik durum akut rejeksiyon ile karışabilmektedir ${ }^{5}$. Yapılan çalışmalarda biyopsi öncesi ve sonrası tanılar arasında \%40'a varan oranlarda farklilıklar bildirilmektedir. Transplant böbreğin histolojik incelenmesi doğru tanı ve tedavi açısından büyük yarar sağlamaktadır6.

Uzun dönemdeki sağkalım ve allograft fonksiyonuna etkili olan faktörler her merkezde farklılıklar göstermektedir. Çalışmamızda ünitemizden takipli renal allograft biyopsi yapılmış olan hastaların sonuçlarının klinik ve patolojik açıdan retrospektif olarak değerlendirilmesi, biyopsi sonuçları ve greft sağ kalımları arasındaki ilişkilerin ortaya konması amaçlanmıştır.

\section{YÖNTEMLER}

Renal Transplantasyon polikliniğinden takipli 2006-2010 yilları arasında renal allograft biyopsi yapılmış olan 70 hasta retrospektif olarak incelemiştir. Biyopsi işlemi deneyimli bir uzman tarafından ultrason rehberliğinde tek kullanımlı 16G otomatik iğne ile yapılmıştır. İki kore biyopsi alınmıştır. Alınan biyopsiler hasta başında x10 büyütmeli lup ile incelenmekte, korteks dokusu olup olmadığı değerlendirilmektedir. Patoloji Anabilim Dalı'na ulaştırılan örnekler immunfloresan inceleme için ayrıldıktan sonra fikse edilerek parafin bloklar elde edilerek ışık mikroskobik inceleme yapılmıștır. 16 hastaya ayrıca $\mathrm{Cd} 4$ boyası yapılabilmiştir. Hastaların biyopsi öncesi işlem onamları bulunmaktaydı. Çalıșma için hastanemiz etik kurulundan onay alınmıştır. Hastalar akut selüler rejeksiyon(ASR), kalsinörin inhibitörü(KNI) 
toksisitesi, intersitisyel fibrozis tübüler atrofi (IFTA), akut tubüler hasar(ATH) ve greft kaybı gelişenler olarak gruplara ayrılarak alt analizleri yapılmıştır.

\section{Istatistiksel Analiz}

Veriler ortalama \pm standart sapma olarak ifade edilmiştir. Nümerik verilerden normal dağılıma uyan parametrik veriler student $t$ testi ile normal dağılıma uymayanlar ise Mann-Whitney $\mathrm{U}$ testiyle değerlendirilmiştir. Bağımlı gruptan elde edilen nümerik verilerin karşılaştırılmasında eşlenmiş örnekli t-testi kullanılmıştır. Kategorik değişkenler ki-kare testi ve Fischer Exact testi ile değerlendirilmiştir. Survi hesaplanmasında Kaplan Meier yöntemi kullanılmıştır. Kategorik faktörlerin sürviye etkisi log-rank analizi ile hesaplanmıştır. Birden çok faktörün surviye etkisi cox regresyon analizi ile değerlendirilmiştir. Hesaplamalarda ve grafiklerin çiziminde SPSS 17.0 (SPSS inc, IL, USA) programı kullanılmıştır. $\mathrm{P}<0.05$ istatistiksel olarak anlamlı kabul edilmiştir.

\section{BULGULAR}

Çalışma kapsamına giren 70 hastanın 51'i erkek, 19'u kadındır. 70 hastaya 94 adet biyopsi yapılmıştır. Hastaların biyopsi

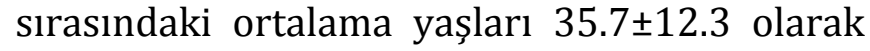
bulunmuştur(Yaş Aralığı:18-60 Ortanca:33.5). Nakillerin 54(\%77.1)'sı canl,, 16(\%22,9)'ü kadavradan yapılmıştır. Hastalarımızda HLA

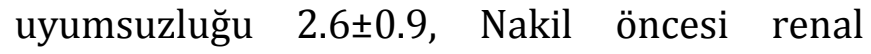
replasman tipi(Preempitif:1, Hemodiyaliz:57, Periton diyalizi:12 hasta), Renal replasman süresi 33.6 \pm 28 aydır. HBsAg (+) 1 hasta, AntiHCV (+) 6 hasta bulunmaktadır.

Hastaların son dönem böbrek yetersizliğinin nedenleri glomerülonefrit-vaskülit(\%38), bilinmeyen(\%27), vezikoüreteral reflü(\%16), hipertansiyon(\%6), ailevi akdeniz ateşi(\%4), diabetik nefropati(\%3), diğer (\%6) idi. Hastaların 52'sine bir kez biyopsi yapılırken 18 hastaya birden çok kere biyopsi yapılmıştır.
Mükerrer biyopsiler mevcut bozukluğun progresyonu nedeniyle yapılmıştır. Biyopsi sonrası transfüzyon gerektirecek masif kanama ve böbrek kaybı gibi major komplikasyon gelişmediği tespit edilmiştir. Biyopsilerin 59'unda biyopsi öncesi en belirgin patolojik bulgu kreatinin yüksekliği, 13'ünde nefrotik düzeyde proteinüri, 13' ünde ise kreatinin yüksekliği ve nefrotik düzeyde proteinüri, 9'unda primer non-fonksiyone greft ve uzamış akut tübüler nekroz idi. Yapılan biyopsilerdeki ortalama glomerül sayısı $17.7 \pm 10.7$ olarak tespit edilmiştir.

Biyopsilerin 22'sinde sadece akut selüler rejeksiyon(ASR), 12'sinde ise ASR+diğer patolojiler tespit edilmiştir. Toplamda $34(\% 36,2)$ biyopsi ile en sik tespit edilen patolojiyi ASR oluşturmaktadır. İntersitisyel fibrozis tübüler atrofi (IFTA)(+), Akut tubüler hasar(ATH)(+), nüks/de novo glomerülonefrit(+) biyopsi sayıları sırasıyla 21(\%22,3), 20(\%21,3), $15(\% 16)$ olarak bulunmuştur.

Birinci yıl öncesi ve sonrası patolojik bulguların görülme sıklıkları incelendiğinde akut rejeksiyon ve kalsinörin inhibitörü toksisitesi görülme sıklıkları açısından anlamlı fark görülmemiştir $(p=0.1)$. İntersitisyel fibrozis tübüler atrofi ve nüks/de novo glomerülonefrit birinci yıl sonrası artarken, akut tübüler hasar ilk yll daha fazla olarak gözlendi $(p=0.01)$ (Tablo 1).

Tablo 1: 1. yıl öncesi ve sonrası biyopsilerde patolojik bulguların görüleme sıklıkları

\begin{tabular}{|lccc|}
\hline & $\begin{array}{c}\text { 1.ylldan } \\
\text { önceki } \\
\text { biyopsiler }\end{array}$ & $\begin{array}{c}\text { 1.ylldan } \\
\text { sonraki } \\
\text { biyopsiler }\end{array}$ & $\mathrm{p}$ \\
\hline $\begin{array}{l}\text { Akut Selüler Rejeksiyon } \\
\text { Kalsinörin İnhibitörü } \\
\text { Toksisitesi }\end{array}$ & 19 & 15 & $\mathrm{AD}$ \\
Akut Tübüler Hasar & 18 & 12 & $\mathrm{AD}$ \\
IFTA & 2 & 2 & 0.01 \\
$\begin{array}{l}\text { Nüks/de novo } \\
\text { Glomerülonefrit }\end{array}$ & 1 & 19 & 0.01 \\
AD: Anlamlı Değil & & 14 & 0.01 \\
\hline
\end{tabular}


Biyopsiler akut rejeksiyon tespit edilen ve edilmeyenler şeklinde iki gruba ayrıldı. Bu iki grubun biyokimyasal parametreleri karşılaştırıldığında istatistikî açıdan anlamlı farklılık tespit edilemedi. Parametreler Tablo 2 de verilmiştir. Biyopsi öncesi klinik ve laboratuvar bulguları ile koyulan ön tanıların $65(\% 69,2)$ biyopside histopatolojik bulgular ile uyumlu olduğu gözlenirken, $29 \quad(\% 30,8)$ biyopside ise değiştiği görülmüștür.

Tablo 2: Biyopsilerinde akut rejeksiyon tespit edilen ve edilmeyenler hastaların biyokimyasal parametreleri

\begin{tabular}{|c|c|c|c|}
\hline & \multicolumn{2}{|c|}{ AKUT SELÜLER REJEKSIYON } & \multirow[b]{2}{*}{$\mathbf{p}$} \\
\hline & $\begin{array}{l}(+) \\
n: 34\end{array}$ & $\begin{array}{c}(-) \\
n: 56\end{array}$ & \\
\hline Üre(mg/dL) & $104.2 \pm 46.3$ & $102.9 \pm 57.1$ & $\mathrm{AD}$ \\
\hline $\operatorname{Kreatinin}(\mathrm{mg} / \mathrm{dL})$ & $3.37 \pm 2.4$ & $3.1 \pm 2$ & $\mathrm{AD}$ \\
\hline Ürik asit(mg/dL) & $6.9 \pm 1.9$ & $6.9 \pm 1.5$ & $\mathrm{AD}$ \\
\hline Kalsiyum(mg/dL) & $8.7 \pm 0.9$ & $8.8 \pm 0.9$ & $\mathrm{AD}$ \\
\hline $\operatorname{Albümin}(\mathrm{g} / \mathrm{dL})$ & $3.4 \pm 0.6$ & $3.4 \pm 0.7$ & $\mathrm{AD}$ \\
\hline Fosfor(mg/dL) & $4 \pm 1.4$ & $4.2 \pm 1.8$ & $\mathrm{AD}$ \\
\hline Hemoglobin(g/dL) & $10.5 \pm 2.2$ & $10.6 \pm 1.9$ & $\mathrm{AD}$ \\
\hline $\begin{array}{l}\text { Total } \\
\text { Kolesterol(mg/dL) }\end{array}$ & $184 \pm 41$ & $194 \pm 49$ & $\mathrm{AD}$ \\
\hline LDL(mg/dL) & $108 \pm 32$ & $111 \pm 40$ & $\mathrm{AD}$ \\
\hline Trigliserid(mg/dL) & $178 \pm 87$ & $170 \pm 94$ & $\mathrm{AD}$ \\
\hline $\mathrm{HDL}(\mathrm{mg} / \mathrm{dL})$ & $40 \pm 11$ & $42 \pm 15$ & $\mathrm{AD}$ \\
\hline
\end{tabular}

Kalsinörin inhibitörü toksisitesi tespit edilen ve edilmeyenler hastalardaki tacrolimus ve siklosporin kullanımı karşılaştırıldığında siklosporin kullananlarda toksisitenin daha fazla olduğu tesbit edildi ( $p=0.002)$ (Tablo 3). Çalışmadaki 4 hasta sirolimus, 2 hasta ise everolimus kullanmakta idi.

Hastaları greft kaybı olanlar ve olmayanlar şeklinde iki gruba ayırarak biyokimyasal ve klinik parametreler açısından karşılaştırıldığında sadece albümin açısından anlamlı farklılık tespit edilmiștir. Biyopsi sırasındaki albümin seviyesi greft kaybı olan grupta anlamlı olarak daha düşük bulunmuştur $(\mathrm{p}<0.03)$. Greft kaybı olan hastalar ile greft fonksiyonlarını kaybetmemiş hastalar arasındaki biyopsi sırasındaki farklar Tablo 4 de verilmiştir.

Tablo 3: Kalsinörin inhibitörü kullanan hastaların biyopsilerinde ilaç ilişkili toksisite bulguları açısından tacrolimus ve siklosporin kullanımının karşılaştırılması

\begin{tabular}{|c|c|c|c|}
\hline & \multicolumn{2}{|c|}{$\begin{array}{c}\text { Kalsinörin İnhibitörü } \\
\text { Toksisitesi }\end{array}$} & \multirow[b]{2}{*}{$\begin{array}{c}\text { Toplam } \\
\text { n:84 }\end{array}$} \\
\hline & $\begin{array}{l}(+) \\
\mathrm{n}: 20\end{array}$ & $\begin{array}{c}(-) \\
\mathrm{n}: 64\end{array}$ & \\
\hline Tacrolimus & 11 & 55 & 66 \\
\hline Siklosporin & 9 & 9 & 18 \\
\hline
\end{tabular}

Tablo 4: Greft kaybı olan hastalar ile greft fonksiyonlarını kaybetmemiş hastalar arasındaki biyopsi sırasındaki farklar

\begin{tabular}{|c|c|c|c|}
\hline & DEVAM & GREFT KAYBI & $\mathbf{p}$ \\
\hline & n:46 & n:24 & \\
\hline Cinsiyet Erkek/Kadın & $35 / 11$ & $16 / 8$ & $\mathrm{AD}$ \\
\hline Transplant sırasındaki yaş & $33.6 \pm 12.3$ & $30 \pm 13.3$ & $\mathrm{AD}$ \\
\hline Biyopsi sırasındaki yaş & $35.9 \pm 12$ & $34.7 \pm 12.6$ & $\mathrm{AD}$ \\
\hline HLA uyumsuzluğu & $2.5 \pm 0,9$ & $2.7 \pm 0.8$ & $\mathrm{AD}$ \\
\hline Renal replasman süresi (ay ) & $36.3 \pm 29.3$ & $28.3 \pm 25$ & $\mathrm{AD}$ \\
\hline Sistolik Kan Basıncı(mmHg) & $124.7 \pm 12.6$ & $131.2 \pm 17.2$ & $\mathrm{AD}$ \\
\hline DiastolikKan Basıncı(mmHg) & $79.7 \pm 8.2$ & $83.3 \pm 7$ & $\mathrm{AD}$ \\
\hline Üre(mg/dL) & $93 \pm 50.2$ & $106.6 \pm 57$ & $\mathrm{AD}$ \\
\hline $\operatorname{Kreatinin}(\mathrm{mg} / \mathrm{dL})$ & $3 \pm 2.1$ & $3.4 \pm 2.6$ & $\mathrm{AD}$ \\
\hline Total Kolesterol(mg/dL) & $190.6 \pm 45.8$ & $188.7 \pm 54.8$ & $\mathrm{AD}$ \\
\hline HDL(mg/dL) & $43 \pm 14.8$ & $39.7 \pm 10.2$ & $\mathrm{AD}$ \\
\hline Trigliserid(mg/dL) & $181.9 \pm 94.8$ & $140.1 \pm 60.1$ & $\mathrm{AD}$ \\
\hline $\mathrm{LDL}(\mathrm{mg} / \mathrm{dL})$ & 107.732.1 & $119.5 \pm 46.5$ & $\mathrm{AD}$ \\
\hline Ürik asit(mg/dL) & $6.8 \pm 1.6$ & $6.7 \pm 1.6$ & $\mathrm{AD}$ \\
\hline Kalsiyum(mg/dL) & $9 \pm 0.8$ & $8.7 \pm 0.9$ & $\mathrm{AD}$ \\
\hline Fosfor(mg/dL) & $3.9 \pm 1.9$ & $4.7 \pm 1.3$ & $\mathrm{AD}$ \\
\hline $\operatorname{Albümin}(g / d L)$ & $3.6 \pm 0.6$ & $3.2 \pm 0.7$ & 0.03 \\
\hline Hemoglobulin(g/dL) & $11 \pm 2.3$ & $10.4 \pm 2$ & $\mathrm{AD}$ \\
\hline Hematokrit(\%) & $32.5 \pm 7$ & $31.8 \pm 6.8$ & $\mathrm{AD}$ \\
\hline
\end{tabular}

AD: Anlamlı Değil 
Çalışmaya alınan hastaların 1 yıllık greft sürvileri $\% 93$, \%5 ylllı greft sürvileri $\% 88$ olarak tespit edilmiștir. Hastaların greft sürvilerinin Kaplan-Meier eğrisi Şekil 1 de verilmiştir. Akut rejeksiyon öyküsü olan ile olmayan hastaların greft sürvileri karşılaştırıldığında rejeksiyon olanlarda greft sürvisinin daha kısa olduğu tespit edildi. $(\mathrm{p}<0.05)$. Şekil 2 de Kaplan-Meier analizi yer almaktadır. Biyopsilerin 13 tanesine $\mathrm{Cd} 4$ boyası yapılmış olup bunların 4'ünde boyanma görülmüștür. Antikor aracılıklı rejeksiyon öyküsü olan bu 4 hastanın 3' nün greft kaybı olmuştur.

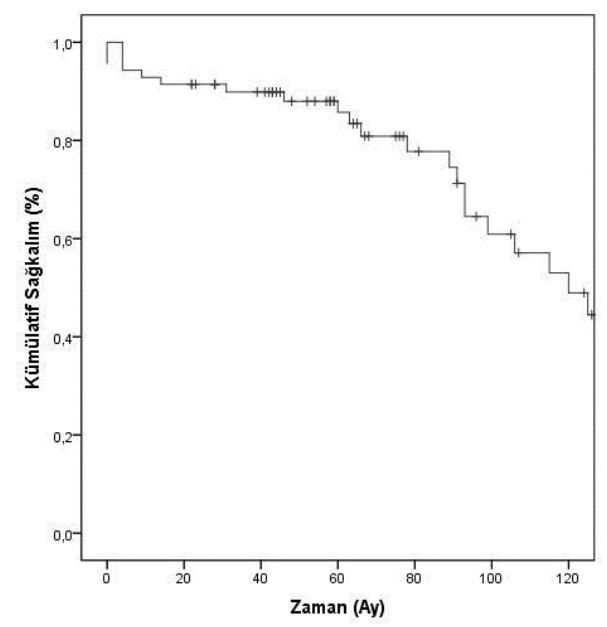

Şekil 1: Çalışmaya alınan hastaların greft sürvisi

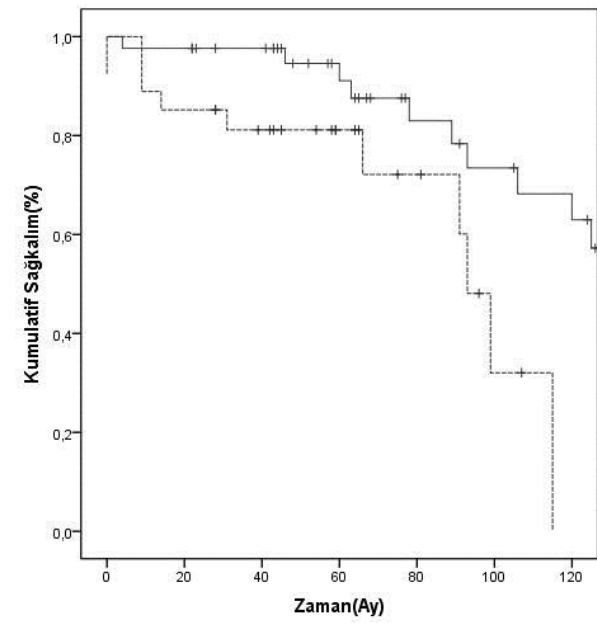

Şekil 2: Akut selüler rejeksiyon öyküsü olan ve olmayan hastaların greft sürvisi $(\mathrm{p}=0.01)$.
Çalışmaya alınan hastalar greft kaybı olanlar ve greft fonksiyonları devam edenler olarak iki gruba ayrıldığında greft kaybı olan grupta IFTA daha fazla görülmüştür $(\mathrm{p}<0.05)$. Ancak kaplanmeier analizinde surviler logrank testi ile IFTA ya göre kıyaslandığında anlamlılı̆̆ını yitirmiştir. Çalışmaya alınan hastalarda KNI toksisitesi, ATH ile greft sürvileri arasında anlamlı fark tespit edilememiştir. Kadavra ve canlıdan yapılan nakiller arasında greft sürvileri arasında anlamlı fark tespit edilememiştir.

\section{TARTIŞMA}

Biyopsi öncesi klinik ve laboratuvar bulguları ile koyulan ön tanıların $65(\% 69,2)$ biyopside histopatolojik bulgular ile uyumlu olduğu gözlenirken, $29(\% 30,8)$ biyopside ise değiştiği görülmüştür. Yaklaşı biyopsilerin üçte birinde farklı bir tanı ile karşılaşılması biyopsi olmadan diğer klinik ve laboratuvar bulguların yetersizliğini göstermektedir. Literatürde biyopsi sonrası ön tanıların \%30 ile \%42 oranında değişebildiği bildirilmektedir ${ }^{7-9}$. AlAwwa IA ve ark. çalışmasında birbirinden habersiz üç ayrı araştırmacının biyopsi öncesi tanısı ile biyopsi sonrası gelen tanıları karşılaştırılmıştır. Çalışmada \%26 oranında uyumsuz öntanı düşünüldüğü tespit edilmiştir ${ }^{10}$.

Bizim hasta grubumuz da ağırlıklı olarak canlıdan nakil yapılan, orta ve genç erkek hastalardan oluşmaktadır. Türkiye'de 2015 yılında nakil yapılan hastaların yalnızca \%20,9 'u kadavra kaynaklıdır. Ülkemizde halen kadavra kaynaklı nakil sayısı yeterli seviyelere ulaşmamıştır ${ }^{11}$. Biyopsi sonrası transfüzyon gerektirecek masif kanama ve başka major komplikasyon gelişmediği tespit edilmiştir. Biyopsi sonrası greft kaybı olmamıştır. Bu da ultrason eşliğinde yapılan renal allograft biyopsisinde komplikasyon oranın az olduğunu göstermektedir. Komplikasyon yönünden bulgularımız literatürde yapılmış çok sayıda çalışma ile uyumludur'12-15. Yeterli dokuya 
ulaşma oranının gayet yüksek olduğu görülmüştür. 94 adet biyopsiden sadece bir tanesinde yetersiz dokuya rastlanmıştır. Yapılan biyopsilerdeki ortalama glomerul sayısı $17.7 \pm 10.7$ olarak tespit edilmiștir. Banff kriterlerine göre biyopsinin tercihen 10 ve daha fazla glomerul içermesi gerekmektedir. Asgari sınır ise 7 'dir ${ }^{16}$. Çalışmamızda bütün işlemlerde 2 kore biyopsi alınmıştır. Yapılan çalışmalarda uygun kriterlerde olan biyopsilerde tek kore biyopsisi ile prediktif değeri yaklaşık \% 90 iken, iki kore biyopsisi ile prediktif değer \%99'a yükseldiği gösterilmiştir ${ }^{17}$. Biyopsilerdeki major endikasyon akut rejeksiyon ile diğer allograft disfonksiyonlarını ayırt etmek olmuştur.

Yapılan 94 biyopsinin 22'sinde sadece Akut selüler rejeksiyon(ASR), 12'sinde ise ASR + diğer patolojiler tespit edilmiştir. Toplamda 34 (\%36,2) biyopside ASR tespit edilmiștir. En sık tespit edilen patolojiyi ASR oluşturmaktadır. ASR birinci yıl öncesinde ve sonrasında benzer oranlarda tespit edilmiştir. ASR' nu ön görmek açısından biyokimyasal parametreler yol gösterici olabilir mi sorusuna cevap için biyopsiler ASR(+) ve (-) olarak ikiye ayrılmıştır. Sonuçta anlamlı fark yaratacak bulgu tespit edilememiştir. Biyopsi yapılan hastalar içinde akut rejeksiyon öyküsü olan ile olmayan hastaların greft sürvileri karşılaştırıldığında rejeksiyon olanlarda greft sürvisinin daha kısa olduğu tespit edilmiştir $(\mathrm{p}<0.05)$. Erken dönem akut rejeksiyon, sık akut rejeksiyon atakları ve tedaviye dirençli akut rejeksiyon greftin uzun dönem survisini belirleyen faktörlerdendir ${ }^{18}$. Ayrıca tekrar eden akut rejeksiyon atakları kronik allograft nefropatisi için risk faktörüdür19,20. Hiç Akut rejeksiyon öyküsü olmayanların greft ömrünün daha uzun olduğu tespit edilmiştir ${ }^{21}$. Biyopsilerin 13 tanesine Cd4 boyası yapılmış olup bunların 4'ünde boyanma görülmüştür. Antikor aracılıklı rejeksiyon öyküsü olan bu 4 hastanın 3' nün greft kaybı olmuştur. Laboratuvarda yeterli miktarda kit olmaması nedeniyle $\mathrm{Cd} 4$ boyasının az sayıda yapılması çalışmanın zayıf noktalarından birisini oluşturmaktadır.

Histolojik olarak kronik allograft nefropatisi intersitisyel fibrozis, tubüler atrofi, glomerüler sklerozis ve vasküler obliterasyon ile karakterizedir22. Banff sinıflamasında kronik allograft nefropatisi için daha çok IFTA terimi kullanılmıştır. $\mathrm{Bu}$ sinıflamaya glomeruler, mezengial matriks ve vasküler değişiklikler dâhil edilmemiştir ${ }^{23}$. Kalsinörin inhibitörü toksisitesi (+) olan biyopsi sayısı 20(\%21,3) olarak bulunmuştur. KNI Toksisitesi(+) ve (-) olan gruplar tacrolimus ve siklosporin kullanımı açısından karşılaştırıldığında siklosporin kullananlarda toksisitenin daha fazla olduğu tesbit edildi ( $\mathrm{p}=0.002)$. Kalsinörin inhibisyonu üzerinde etki eden iki ilaç olan tacrolimus ve siklosporinin histopatolojide benzer bozukluklara neden olduğu bilinmektedir. Ancak takrolimus sikloporin'e göre potent, terapötik aralığı geniş, zayıf vazokonstriktör ve intersitisyel fibrozis yapıcı etkisi daha düşüktür ${ }^{24}$.

Ayrica m-TOR inhibitörü olarak çalışmamızdaki 4 hasta sirolimus, 2 hasta ise everolimus kullanmakta idi.

Greft kaybı olan hastalar ile greft fonksiyonlarını kaybetmemiş hastalar arasındaki biyopsi sırasındaki farklar incelendiğinde biyopsi sırasındaki albümin seviyesi greft kaybı olan grupta anlamlı olarak daha düşük bulunmuştur $(\mathrm{p}=0.03)$. Bu bulgu greft survi açısından değerlendirildiğinde anlamlılığını korumuştur. Ayrıca biyopsi sırasında proteinürisi olan hastalar dışlanarak tekrar cox regresyonu yapıldığında anlamlılığını korumaya devam etmiştir. Literatürdeki çalışmalar incelendiğinde, böbrek naklinin ilk yılındaki albümin değerinin greft survisi açısından bağımsız prediktif değeri olduğu belirtilmiştir ${ }^{25}$. Hastaların pretransplant serum albümin seviyesinde her 0.2 g/dl artış ile transplant sonrası mortalitede \%13 azalma bildirilmiştir ${ }^{26}$. 2015 yılında 
yapılan bir çalışmada böbrek nakli sonrası 1. yıl albumin seviyesi normal aralıkta olan (3.5$5.5 \mathrm{~g} / \mathrm{dL}$ ) hastaların uzun dönem takipleri incelenmiştir. Albümin seviyesinin $4.6 \mathrm{~g} / \mathrm{dL}$ altında olması bile uzun dönemde kötü gidiş ile ilişkili bulunmuștur ${ }^{27}$.

Protokol biyopsileri konusunda kesin bir fikir birliği olmaması nedeniyle şu an için ünitemizin rutin uygulamasinda yer almamaktadır. Kadavra ve canlıdan yapılan nakiller arasında greft sürvileri arasında istatistiksel anlamlı fark tespit edilememiștir. Dokuz Eylül Üniversitesinin renal transplant sağkalımlarının incelendiği bir çalışmada da canlı ve kadavra kaynaklı nakiller arasında sağkalım açısından istatistiksel anlamlı farklılık bulunmamıştır ${ }^{28}$.

Ünitemizde yapılan ve 20 yıllı nakil deneyimini değerlendiren bir çalışmaya göre greft sürvisi 1 yll için \%87,5, 5 yll için \%78,3 tespit edilmiştir. Bu çalışmada 2000 yılı sonrası nakillerde greft survisi daha iyi bulunmuştur ${ }^{29}$. Çalışmamızda 2006 yılı sonrası yapılan biyopsiler olması nedeniyle greft sürvilerimiz ünitemizin genel ortalamasının üstünde gözlenmiştir.

Sonuç olarak; biyopsilerin yaklaşık üçte birinde öntanıdan farklı bir tanı ile karşılaşılmıştır. Bu da biyopsi olmadan diğer klinik ve laboratuvar bulguların yetersizliğini göstermektedir. Greft survisini ön görmede biyopsi önemli yer teşkil etmektedir. Non-invaz olarak biyopsi öncesi bakılan serum albumin seviyesi greft kaybını öngörmede bir parametre olarak değerlendirilebilir.

Çıkar Çatışması Beyanı: Yazarlar çıkar çatışması olmadığını bildirmişlerdir.

Finansal Destek: Bu çalışma her hangi bir fon tarafından desteklenmemiştir.

Declaration of Conflicting Interests: The authors declare that they have no conflict of interest.
Financial Disclosure: No financial support was received.

\section{KAYNAKLAR}

1. Ghanta M, Jim B. Renal Transplantation in Advanced Chronic Kidney Disease Patients. Med Clin North Am. 2016; 100: 465-76.

2. Meier-Kriesche HU, Schold JD, Srinivas TR, Kaplan B. Lack of improvement in renal allograft survival despite a marked decrease in acute rejection rates over the most recent era. Am J Transplant. 2004; 4: 378-83.

3. Gray DW, Richardson A, Hughes D et al. A prospective, randomized, blind comparison of three biopsy techniques in the management of patients after renal transplantation. Transplantation. 1992; 53: 1226-32.

4. Wilczek HE. Percutaneous needle biopsy of the renal allograft. A clinical safety evaluation of 1129 biopsies. Transplantation. 1990; 50: 790-7.

5. Matas AJ, Sibley R, Mauer M, et al. The value of needle renal allograft biopsy. I. A retrospective study of biopsies performed during putative rejection episodes. Ann Surg. 1983; 197: 226-37.

6. Thaunat O, Legendre C, Morelon E, Kreis H, MamzerBruneel MF. To biopsy or not to biopsy? Should we screen the histology of stable renal grafts? Transplantation. 2007; 84: 671-6.

7. Kiss D, Landmann J, Mihatsch $M$, et al. Risks and benefits of graft biopsy in renal transplantation under cyclosporin-A. Clin Nephrol. 1992; 38: 132-4.

8. Kon SP, Templar J, Dodd SM, Rudge CJ, Raftery MJ. Diagnostic contribution of renal allograft biopsies at various intervals after transplantation. Transplantation. 1997; 63: 547-50.

9. Pascual M, Vallhonrat $H$, Cosimi AB, et al. The clinical usefulness of the renal allograft biopsy in the cyclosporine era: a prospective study. Transplantation. 1999; 67: 737-41.

10. Al-Awwa IA, Hariharan S, First MR. Importance of allograft biopsy in renal transplant recipients: correlation between clinical and histological diagnosis. Am J Kidney Dis. 1998; 31: S15-8.

11. Süleymanlar G, Ateş K, Seyahi N. Türkiye 2015 Yılı Ulusal Nefroloji, Diyaliz ve Transplantasyon Kayit Sistemi Raporu. Ankara:Türk Nefroloji Derneği Yayınları, 2016; 51-60.

12. Beckingham IJ, Nicholson ML, Kirk G, Veitch PS, Bell PR. Comparison of three methods to obtain percutaneous needle core biopsies of a renal allograft. Br J Surg. 1994; 81: 898-9. 
13. Erturk E, Rubens DJ, Panner BJ, Cerilli JG. Automated core biopsy of renal allografts using ultrasonic guidance. Transplantation. 1991; 51: 1311-2.

14. Mahoney MC, Racadio JM, Merhar GL, First MR. Safety and efficacy of kidney transplant biopsy: Tru-Cut needle vs sonographically guided Biopty gun. AJR Am J Roentgenol. 1993; 160: 325-6.

15. Preda A, Van Dijk LC, Van Oostaijen JA, Pattynama PM. Complication rate and diagnostic yield of 515 consecutive ultrasound-guided biopsies of renal allografts and native kidneys using a 14-gauge Biopty gun. Eur Radiol. 2003; 13: 527-30.

16. Solez K, Colvin RB, Racusen LC, et al. Banff 07 classification of renal allograft pathology: updates and future directions. Am J Transplant. 2008; 8: 753-60.

17. Colvin RB, Cohen AH, Saiontz C, et al. Evaluation of pathologic criteria for acute renal allograft rejection: reproducibility, sensitivity, and clinical correlation. J Am Soc Nephrol. 1997; 8: 1930-41.

18. Lindholm A, Ohlman S, Albrechtsen D, et al. The impact of acute rejection episodes on long-term graft function and outcome in 1347 primary renal transplants treated by 3 cyclosporine regimens. Transplantation. 1993; 56: 307-15.

19. Emiroglu R, Yagmurdur MC, Karakayali F, et al. Role of donor age and acute rejection episodes on long-term graft survival in cadaveric kidney transplantations. Transplant Proc. 2005; 37: 2954-6.

20. Flechner SM, Modlin CS, Serrano DP, et al. Determinants of chronic renal allograft rejection in cyclosporine-treated recipients. Transplantation. 1996; 62: 1235-41.

21. Hariharan S, Johnson CP, Bresnahan BA, et al. Improved graft survival after renal transplantation in the United States, 1988 to 1996. N Engl J Med. 2000; 342: 605-12.
22. Ponticelli C. Chronic allograft nephropathy. In: Ponticelli C(editor). Medical complication of kidney transplantation: Informa UK.; 2007: 105-7.

23. Racusen LC, Solez K, Colvin RB et al. The Banff 97 working classification of renal allograft pathology. Kidney Int. 1999; 55: 713-23.

24. Nast CC, Cohen AH. Pathology of Kidney Transplantation. In: Danovitch GM(editor). Handbook of Kidney Transplantation: Lippincott Williams \& Wilkins; 2009: 312-3.

25. Dahlberg R, Muth B, Samaniego M, et al. One-year serum albumin is an independent predictor of outcomes in kidney transplant recipients. J Ren Nutr. 2010; 20: 392-7.

26. Molnar MZ, Kovesdy CP, Bunnapradist S, et al. Associations of pretransplant serum albumin with post-transplant outcomes in kidney transplant recipients. Am J Transplant. 2011; 11: 1006-15.

27. Oh IH, Park JS, Lee CH, Kang CM, Kim GH. Prognostic Significance of 1-Year Serum Albumin Levels Within the Normal Range After Kidney Transplantation. Artif Organs. 2015; 39: 965-72.

28. Çoban Ş, Yıldız S, Bozkaya E, ve ark. Böbrek Nakli Alıcılarının Morbidite, Hasta ve Greft Sağkalımı Yönünden Değerlendirilmesi: Dokuz Eylül Üniversitesi Hastanesi Deneyimi. Turkish Nephrology, Dialysis and Transplantation Journal. 2016; 26: 1-7.

29. Soylu H, Oruc M, Demirkol OK et al. Survival of renal transplant patients: data from a tertiary care center in Turkey. Transplant Proc. 2015; 47: 348-53. 